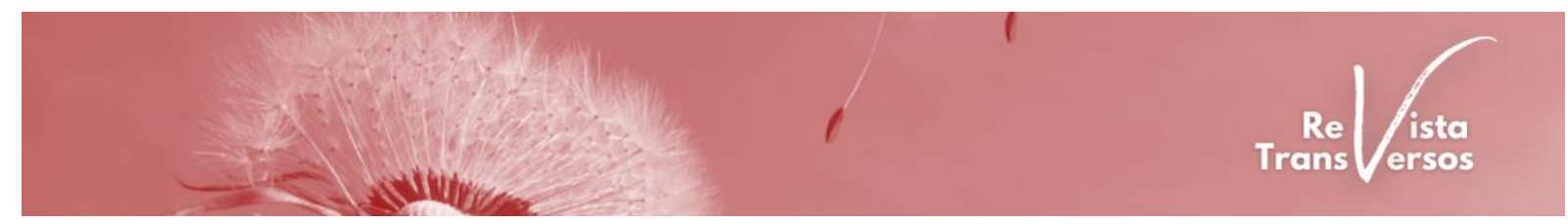

DOI: $10.12957 /$ transversos.2021.58416

\title{
GÊNERO E FEMINISMO (s) AFRICANO (s) ${ }^{1}$ \\ GENDER AND AFRICAN FEMINISM (s)
}

Dayane Augusta Santos da Silva

Instituto Federal de Brasília (IFB) - Brasil

daygusta@gmail.com

\section{Resumo:}

Este artigo realiza discussão teórica-conceitual acerca as articulações das categorias mulher-gênerofeminismos. Parto prioritariamente dos estudos de intelectuais africanas inseridas no campo dos estudos de gênero no continente africano. Utilizo o termo "feminismos africanos" para referir-me a material bibliográfico produzido por feministas negras africanas, acadêmicas negras africanas e ativistas que, independentemente do seu país de origem, no continente ou na Diáspora, refletem partindo do ponto de vista africano, como um "conhecimento endógeno", embora reconhecendo a imensa heterogeneidade que opera dentro dos limites deste termo. As intelectuais africanas concentram-se na experiência das mulheres africanas e ressaltam as diferentes formas de opressão as quais estas mulheres estão sujeitas, sob outra ótica. $\mathrm{O}$ esforço aqui não é de categorizar ou classificar as obras das intelectuais, em alguns casos autodeclaradas feministas africanas, mas analisar algumas implicações teóricas que o uso do termo trás.

Palavra-Chaves: Mulher; Angola; Intelectuais africanas; Feminismos africanos.

\section{Abstract}

This article carries out a theoretical-conceptual discussion about the articulations of the categories woman-gender-feminisms. I start primarily from the studies of African intellectuals inserted in the field of gender studies on the African continent. I use the term "African feminisms" to refer to bibliographic material produced by black African feminists, black African scholars and activists who, regardless of their country of origin, on the continent or in the Diaspora, reflect from an African point of view, as a "endogenous knowledge", while acknowledging the immense heterogeneity that operates within the limits of this term. African intellectuals focus on the experience of African women and highlight the different forms of oppression to which these women are subjected, from another perspective. The effort here is not to categorize or classify the works of intellectuals, in some cases self-declared African feminists, but to analyze some theoretical implications that the use of the term brings.

Keywords: Woman; Angola; African intellectuals; African feminisms.

Este artigo é um extrato da parte teórica (primeiro capítulo) de minha tese de Doutorado, em vias de finalização, no Programa de Pós-Graduação em História da Universidade de Brasília, sobre a experiência de mulheres angolanas na luta anticolonial, sob a orientação do Prof. Dr. Anderson Oliva. Uma das questões presentes na pesquisa foi a de ler e compreender as produções de intelectuais africanas e africanos voltados ao estudo das experiências constitutivas da história das mulheres no continente. A ideia foi refletir como a pesquisa no continente africano pode ser mais informada pelos interesses e condicionalismos locais.

\footnotetext{
${ }^{1}$ Por tratar-se de artigo e falta de experiência no tema, a presente reflexão não está incluindo o debate da identidade queer ( LGBTQIAP+ e dissidência sexual) em África, embora esteja dentro do debate feminista.
} 
Tendo em vista o tema de minha pesquisa, parto de Angola para problematizar as categorias acima referidas - mulher-gênero-feminismos - sem perder de vista a problemática em torno dos estudos de gênero no continente africano, e na Diáspora. Tendo em conta os objetivos do texto, mas também em consequência de tempo e espaço, não adensarei os temas referidos.

O intento é pautar reflexões substantivas no estudo de gênero no continente. $\mathrm{O}$ artigo divide-se em três partes. No primeiro momento, realizo breve reflexão sobre o contexto da luta por direitos e dos estudos de gênero em Angola. No segundo amplio o debate, entendendo e analisando criticamente a categoria "mulher", partindo principalmente dos estudos de Oyèrónké Oyěwùmí. Por último, procuro interseccionar feminismos, pautando algumas problemáticas em torno do gênero e da raça.

\section{Breve histórico das lutas de/por mulheres em Angola}

Em Angola, na acepção tradicional de luta contra as opressões e pró-direitos das mulheres, os feminismos africanos constituíram-se a partir dos anos 70 da segunda metade do século $\mathrm{XX}^{2}$, muito embora o debate sobre o feminismo (s) africano (s) só tenha entrado na esfera pública quatro ou cinco anos depois da guerra civil (MOUZINHO; CUTAIA, 2017: p. 10). De acordo com a historiografia especializada, sabe-se que a luta pela igualdade de direitos adquiriu progressiva expressão no quadro da luta armada. Desde então, as mulheres angolanas passaram a ser participantes ativas em várias atividades e campos de combate, "granjeando, assim, em parte, a admiração e os respeitos dos seus "camaradas" ou companheiros, porém pouco se sabendo da sua participação política ativa” (FERREIRA, 2018: p. 54).

O feminismo, nos termos conhecidos no Ocidente, teve pouca expressividade no contexto angolano. Não à toa, nas notícias dos jornais pesquisados entre os anos de 1960 e 1975, encontrei apenas vestígios das pautas de movimentos feministas do exterior, como EUA e Europa. Em um dos jornais, como é o caso do Província de Angola, de fevereiro de 1972, apenas uma foto pequena de Ângela Davis, com os dois dentes da frente pintados, e uma curta referência que discorria sobre sua dispensa "sob fiança e após 16 meses de prisão". Declara Davis na nota: "sinto-me excelentemente capaz de defender até ao fim a minha causa justa” ${ }^{3}$.

\footnotetext{
${ }^{2}$ Embora as experiências de emancipação de mulheres no continente remetam ao período pré-colonial, refiro-me especificamente as discussões que envolvem os debates sobre emancipação, empoderamento, as problemáticas da divisão sexual do trabalho, desenvolvimento e violências baseados no gênero. Temas que entram para a cena pública com maior incidência desde o contexto de libertação e depois, com a independência.

${ }^{3}$ Arquivo da Biblioteca Nacional de Angola. Jornal Província de Angola, fevereiro de 1972.
} 
No entanto, é inegável que no século XX houve sim "movimentos" de mulheres angolanas nas lutas de independência que combateram ao "lado dos homens", como recorrentemente aparece nos relatos de época e que, a partir daí, passaram a teorizar sobre suas próprias experiências ${ }^{4}$.

As lutas de libertação no continente serviram como base de formação para os feminismos africanos, portanto estes se confundem e se inserem também na luta política pela independência (FERREIRA, 2018: p. 54). Contudo, como Mc Fadden (2020: p. 310) explica, dado a especificidade do movimento de mulheres que se definiu por ideologias nacionalistas e noções normatizadas de igualdade de gênero, existiram tensões entre aquelas que negociavam com o Estado e certas instituições patriarcais; e aquelas que optaram por uma postura feminista mais radical a respeito da postura do Estado com mulheres. Suponho que é nessa intersecção que o feminismo emerge, na formação de um campo intelectual e interventivo de análise e reflexão mais direta acerca as opressões de gênero.

Pode-se considerar que a luta pela igualdade de direitos enquanto conquista coletiva de mulheres remonta ao século XIX, assim como o vocábulo "feminismo". Nesse período", principalmente nos países de colonização portuguesa em África, são poucos os estudos conhecidos sobre como mulheres "regiam e podiam reagir de várias formas aos costumes que a sociedade da época lhes impunha” (REIS, 1987: p. 54). Muito embora, não possamos esquecer, de que a "força das mulheres em África - através do modo como, há muito tempo, se organizam as estruturas familiares com linhagens matriarcais - é um exemplo de afirmação de poder das mulheres" (BAMISILE, 2013: p. 265).

Dya Kassembe (2010), por exemplo, escritora angolana ainda pouco conhecida na academia brasileira, possui produção literária e ensaística importante sobre Angola e organizou um livro de relatos e memórias sobre a tradição das mulheres de Kisama, antiga região angolana que se estendia por um grande território do Kwanza Norte ao Kwanza Sul.

\footnotetext{
${ }^{4}$ Utilizo o termo "movimentos", deliberadamente, para indicar a mobilização de mulheres em várias direções e atividades; evocar as associações destas dinâmicas propriamente femininas com a política.

${ }^{5}$ Segundo Maria do Céu Carmo Reis (1987. p.160), foi especialmente no século XIX que as mulheres pertencentes à sociedade crioula desempenharam um papel ativo no nível das redes ideológicas primárias, como a família, grupos de aliança, associações de solidariedade, etc. Da profusão dessas práticas, emergirá figuras simbólicas ricas de significados, das mulheres nutridoras, fundadoras, conspiradoras, o que ritmou os ciclos de vida e ritualizou as trocas humanas.
} 
No livro intitulado As mulheres honradas e insubmissas de Angola, Kassembe (2010) versa sobre as "mulheres da Angola pré-colonial, do processo de aprendizado que elas vivenciavam com as mais velhas e das estratégias que encontravam para, a partir do espaço que a tradição lhes conferia, construírem sua autonomia e valorização social". A autora busca "recuperar a própria história para fortalecer a identidade e promover a autonomia” (RABELO, 2017: p. 126). Quantas situações outras devem ter existido sem que conheçamos as formas de contestação à ordem vigente? Podemos imaginar, já que muito pouco sabemos sobre a posição da mulher em Angola pré-colonial ${ }^{6}$.

Para o século XX, como destaca a socióloga senegalesa Fatow Sow (1997), as lutas anticoloniais orientaram as mulheres em direção a interesses mais ligados às questões políticas do país do que à pauta feminista de luta contra o patriarcado. Eram militantes dos movimentos de libertação e, na luta armada, reagiram contra a opressão do poder colonial e, como membras partidárias, dificilmente desaprovavam o poder patriarcal dos líderes da independência (CIRNE, 2017: p. 110)

Após o período de luta armada, entre os anos de 1960-1975, e avaliações críticas resultantes do processo de independência, progressivamente, abriu-se um maior espaço para o pensamento feminista na sociedade em geral, aquele que situava o debate de gênero em e a partir das questões e experiências do continente africano.

A matéria publicada no jornal Diário de Luanda, de 04 de julho de 1975, dá mostras desse movimento de maior abertura política ao pensamento feminista (s) africano (s), em Angola. Nesta, em sessão intitulada "atualidade africana", reclamava-se do acúmulo de funções econômicas e sociais executadas pelas mulheres africanas. O texto, resultado da elaboração de Documento da Comissão Econômica para a África (C.E.A), versa sobre o papel das mulheres na valorização do continente africano. Postula: "a sociedade africana continua a ser essencialmente tradicional e os setores da economia assenta em grande parte nas mulheres. Contudo, não é reconhecida"?

\footnotetext{
${ }^{6}$ Sobre a questão da mulher na História de Angola pré-colonial, existem os estudos recentes das investigadoras brasileiras Renata Costa (2014) e Vanessa dos Santos (2018), remontando a finais do século XIX e princípios do século XX. Mais voltado para o século XVIII, as pesquisas da historiadora brasileira Selma Pantoja (2004) e do historiador canadense José Curto (2016) também devem ser consideradas.

Ao longo do tempo, é bibliografia que vem expandindo o conhecimento sobre este período específico da História de Angola, embora as lacunas sejam ainda imensas.

${ }^{7}$ Jornal Diário de Luanda. 04 de julho de 1975.
} 
A reportagem apresenta ainda dados estatísticos estimando que, na data de publicação do texto, $60 \%$ a $80 \%$ dos trabalhos agrícolas em África eram executados por mulheres, que mais de $80 \%$ das pequenas comerciantes também eram mulheres e mais de $50 \%$ do trabalho efetuado no desenvolvimento de trabalhos comunitários (construção de estradas, escolas maternais e primárias e centros de aldeia) também eram confiados as mulheres ${ }^{8}$.

O referido artigo enfatizava ainda o poder das famílias numerosas na maior parte de África, que além de gerar filhos, conferia a mulher africana um certo prestígio social. No entanto, nem por isso, independente da gravidez, parto, aleitamento, deixava de trabalhar nos campos ou no mercado. Ou seja, identificava que a mentalidade e opiniões concernentes ao papel delas nas sociedades africanas eram profundamente marcados pela tradição. A publicação cita exemplos da situação da mulher no Marrocos, Zâmbia, Serra Leoa, Etiópia, África do Sul, Senegal e Costa do Marfim, Libéria, Gana e Nigéria, no objetivo de defender a ideia de que a emancipação das mulheres africanas teria que ser em escala continental. O que envolvia o reclamo e busca de melhores condições sociais e econômicas para mulheres, nas condições de trabalho, no reconhecimento de seu papel para o desenvolvimento da economia e a luta contra opressão.

Sem autoria individualizada, estas indagações provinham de grupos de mulheres emergentes, jovens, pensadoras, não declaradamente feministas, embora com pautas informadoras desse movimento, algumas delas tendo protagonizado a luta de libertação. Como referido anteriormente, questionamentos que possibilitaram maior abertura às agendas que davam centralidade as mulheres na busca por direitos. O tema da emancipação feminina, por exemplo, destaca-se principalmente no contexto do pós-independência, como um dos pontos chaves no esforço de igualdade de gênero.

As mulheres buscaram reafirmar sua posição na dupla luta de combate ao colonialismo e patriarcalismo, porém demarcando suas diferenças e desconfianças em relação ao "feminismo". O que sugere uma hesitação de teor terminológico, e também justificou à procura por uma variante africana, que expressasse as críticas das africanas ao feminismo ocidental, considerado "exclusivamente dependente da divisão binária de gênero, e suas consequências em termos da memorização da mulher" (BAMISILE, 2013: p. 262-3).

\footnotetext{
${ }^{8}$ Idem.
} 
Em Angola, além da ação de mulheres sem agremiações políticas, e das organizações de mulheres tradicionalmente associadas aos movimentos de libertação ${ }^{9}$, hoje partidos políticos, existe o Ondjango feminista ${ }^{10}$. O coletivo é uma organização autônoma, independente, formada em junho de 2016, em Luanda, pelas membras co-fundadoras Aurea Mozinho e Sizaltina Cutaia (2017). As feministas do Ondjango reivindicam o direito e espaço de (re) existência do feminismo africano no país.

É um grupo pequeno, em termos quantitativos, mas com ações e estratégias importantes na demarcação de lugares na sociedade angolana. Formado basicamente por mulheres jovens e intelectualizadas, muitas delas filhas da geração das mamãs que estiveram presentes nas duas grandes guerras, a de libertação e civil.

Estas feministas têm pautado problemas reais e presentes do mundo contemporâneo angolano, como por exemplo a questão da precarização do trabalho feminino, economia informal, assédio sexual, violência doméstica, aborto e outros temas que, aos poucos, ganham espaço na esfera pública ${ }^{11}$. O que fica expresso nos artigos publicados no site do coletivo, indicação de obras de pensadoras feministas africanas e filmes que captam as nuanças do cotidiano das mulheres no continente ${ }^{12}$.

Ao expressar o compromisso com uma "agenda feminista transformadora", as mulheres do Ondango reafirmam posição política presente na carta de princípios feministas para as feministas africanas (MOUZINHO; CUTAIA, 2017: p. 8) ${ }^{13}$.

\footnotetext{
${ }^{9}$ Organização das Mulheres Angolanas - OMA/MPLA; Liga da Mulher Angolana - LIMA/UNITA e a Associação da Mulher Angolana - AMA/FNLA.

${ }^{10}$ Ondango é Palavra Umbumdu que representa o lugar onde a família ou comunidade reúne-se para compartilhar histórias e resolver problemas (MOUZINHO; CUTAIA, 2017: p. 7).

${ }^{11} \mathrm{Em}$ artigo intitulado "Muhatu" (mulher) e a virada do spoken word em Angola, a pesquisadora carioca Miriane Peregrino abre espaço para as discussões de gênero focando no universo feminino e chama atenção para as preocupações das angolanas com a igualdade de gênero. Elas criam um concurso de poesia falada exclusivamente feminino, visto o cenário de pouca participação de mulheres poetas nos concursos de poesia falada. Dado as dificuldades inerentes a experiência de muitas angolanas, marcadas por impedimentos mais imediatas, a exemplo do lugar de classe social e econômica de muitas das poetas que, também por falta de iluminação pública, não podem sair à noite sozinhas, além da falta de ônibus, itinerários e horários de circulação mais específicos, que poderia garantir maior presença das mulheres nos espaços de poesia noturno, estão em menor presença. Para a investigadora, é nestes espaços onde elas constroem uma "rede de apoio e empoderamento feminino", e combatem estereótipos. (PEREGRINO, 2019)

12 Para mais informações sobre o tema, consultar o site do coletivo. Disponível em https://www.ondjangofeminista.com/quemsomos. Acesso em 30/07/2021.

${ }_{13}$ Carta de princípios feministas para as feministas africanas. Disponivel em https://www.geledes.org.br/wpcontent/uploads/2017/04/AFF-Feminist-Charter-Digital-\%E2\%80\%93-Portuguese.pdf Acesso em 08/112018, p. 12.
} 
$\mathrm{Na}$ carta, destacaram a importância do reconhecimento das memórias de suas ancestrais cujos nomes raramente são registrados nos livros de História e insistiram na ideia de que um feminismo importado do Ocidente para a África é um profundo insulto ${ }^{14}$. Afirmaram as ativistas: "somos mulheres africanas - vivemos aqui em África e mesmo quando vivemos em outro lugar, o nosso foco é sobre a vida das mulheres africanas no continente. A nossa identidade feminista não se qualifica com "se", "mas" ou "porém”. Somos feministas". Ponto" ${ }^{15}$. As feministas africanas concentram-se na experiência das mulheres africanas e ressaltam as diferentes formas de opressão as quais estas mulheres estão sujeitas, sob outra ótica. Reitera a feminista angolana Âurea Mouzinho $(2018)^{16}$ :

Começar a questionar essa ideia de que o feminismo sai do ocidente para a África ou do Ocidente para o Oriente, que é um presente que as mulheres ocidentais nos deram, dão as mulheres africanas. (...). Sim, as palavras, a nomenclatura, é uma nomenclatura ocidental, né!? nós estamos a falar em português, então há certas coisas que a nomenclatura não existe na nossa cultura, nas nossas culturas, várias culturas africanas. E isso não podemos negar, mas acho que a prática de luta contra a injustiça, a prática de luta contra a injustiça de gênero não é alheia aos nossos contextos africanos. Mesmo, tipo, se tivemos a pensar no que o feminismo quer fazer, que é a valorização da mulher eu acho que é até uma luta, no contexto africano, bem anticolonial, porque, pega o exemplo de Moçambique, que existem práticas culturais que tem essa ideia de valorizar a sexualidade feminina mas que no contexto colonial foram reprimidas. Então o feminismo africano quer resgatar esses aspectos positivos da cultura. (...) então, acho que é um pouquinho disso, o feminismo africano vai resgatar esses aspectos positivos da cultura e olhar para a cultura também de uma maneira crítica e dizer oh pá, se calhar existem outros aspectos que nós não queremos manter. Então, é um exercício de resgaste mais também de construção de coisas novas.

As ativistas do Ondango portanto, reivindicam o direito a teorizar, escrever e formular estratégias por si mesmas como feministas angolanas refletindo acerca sua própria realidade. Para tanto, não desassociam a luta de mulheres do passado do continente, tanto dos contextos précoloniais diversos, passando pela escravidão, imperialismo, colonização, lutas de libertação e etc. Para elas, o patriarcado não funciona sozinho, mas sim com outras estruturas, então o (s) feminismo(s) africano(s) abarca questões que estão além das opressões de gênero. As feministas deste coletivo contribuem com a politização dos debates.

\section{Notas sobre os feminismos africanos}

\footnotetext{
${ }^{14}$ Carta de princípios feministas para as feministas africanas. Disponivel em https://www.geledes.org.br/wpcontent/uploads/2017/04/AFF-Feminist-Charter-Digital-\%E2\%80\%93-Portuguese.pdf Acesso em 08/112018, p. 12 .

${ }^{15}$ Ibidem, p. 6.

16 Disponivel em https://www.onomedissoemundo.com/2018/10/ondea-010-encontro-angola/. Acesso em $26 / 07 / 2021$
} 
Os feminismos africanos são construídos em África e na Diáspora e embora remetam para a ideia de uma voz única, coletiva, dizem respeito a realidades específicas informadoras da diversidade do continente, composto por 54 países.

As teorias das/sobre as feministas africanas nos convidam a questionar os lugares de produção de conhecimento e conceitos feministas hegemônicos, centrados nas mulheres ocidentais, de classe média, ou elite, brancas, educadas e urbanas. Pois, conforme ressalta Narayan, se as feministas "falham em ver os contextos de suas teorias, pressupondo que sua perspectiva tem validade universal, tendem a participar da dominação que a cultura ocidental tem exercido sobre culturas não ocidentais” (NARAYAN, 1997: p. 284).

Embora conceitualmente o "feminismo" construa-se "a partir das resistências, derrotas e conquistas que compõem a História da mulher, cujas lutas e estratégias estão em permanente processo de re-criação" (ALVES; PITANGUY, 1991: p. 74); a categoria social "mulher” não é universal, formas de opressão e igualdade estão presentes na sociedade de formas diferenciadas (OYĚWÙMÍ, 2018. p. 173). O que assevera o valor da diferença e compreende os feminismos em sua pluralidade.

$\mathrm{Na}$ busca por descolonizar o conhecimento produzido no mundo ocidental, em Conceitualizando o gênero: os fundamentos eurocêntricos dos conceitos feministas e o desafio das epistemologias africanas, Oyèrónké Oyěwùmí, pesquisadora nigeriana e professora na Stony Brook University, em Nova York (EUA), explica que é necessário interrogar o gênero e os conceitos aliados com base nas experiências e epistemologias africanas ${ }^{17}$. Critica o uso do gênero como modelo explicativo e universalizante para compreender a subordinação e opressão das mulheres e afirma que o gênero, assim como a raça, é, antes de tudo, uma construção sociocultural (OYĚWU̇MÍ, 2018: p. 173).

Ou seja, os grupos e sujeitos sociais, inscritos em determinados contextos e culturas, têm condições diferenciadas. E elaboram o feminismo a partir das relações coletivas com seus grupos de pertença, na busca por direitos. O que significa compreender que gênero e raça não podem ser analisadas da mesma forma em todas as sociedades ${ }^{18}$.

\footnotetext{
${ }^{17}$ Não existe tradução de sua obra para o português, apenas capítulos do livro, no original escrito em inglês. De sua obra principal existe tradução para o espanhol. OYĚWÙMÍ, 2017.

${ }^{18} \mathrm{Tal}$ fato, inclusive, é ponto curioso na carta de princípios feministas para as feministas africanas, resultado do Fórum Feminista Africano, ocorrido em Gana, em 2006. As feministas africanas se reconhecem como parte de um movimento feminista mundial contra a opressão patriarcal em todas as suas formas, afirmando que suas experiências
} 
Oyěwùmí (2018) expõe que, provavelmente, a crítica mais importante das articuladoras feministas de gênero seja aquela feita pelas estudiosas afro-americanas que além de ter sido pioneiras em questionar a agenda desse feminismo ocidentalista, insistiram que, nos Estados Unidos, o gênero não poderia ser compreendido fora da intersecção entre as categorias de raça e da classe. Tal posição "levou à necessidade de insistir na diferenciação entre as mulheres e de teorizar múltiplas formas de opressão, particularmente aquelas nas quais as desigualdades de raça, gênero e classe são evidentes" (OYĚWÙMÍ, 2018: p. 173).

A autora questiona conceitos usuais nas teorias de gênero por serem baseados no modelo de família nuclear patriarcal "euroamericana”, praticamente "alienígena” para algumas regiões da África centro-ocidental. Explica a pesquisadora que "o problema não é que a conceituação feminista comece com a família, mas que ela nunca transcenda os estreitos limites da família nuclear" (OYĚWU̇MÍ, 2018: p. 176), quando na perspectiva africana existem diferentes organizações familiares.

Isto sugere que a lógica da família nuclear patriarcal, a qual muitas vezes o feminismo tradicional se ancora, é uma forma de família inapropriadamente universalizada, o qual não se ajusta a realidades diversas e distintas como as africanas.

A pesquisadora expõe que o entendimento de conceitos feministas, como o gênero, para analisar as realidades africanas marca o desafio destes novos estudos. A interpretação do gênero operando como inerente à natureza dos corpos, de maneira binária, masculino/feminino, homem/mulher, objetivo/subjetivo, racional/irracional, razão/emoção e o consequente privilégio masculino, que hierarquicamente ocupa posição superior, como categoria definidora, é externo a muitas culturas africanas.

Ou seja, endossa a autora, "quando as realidades africanas são interpretadas com base em demandas ocidentais, o que consideramos são distorções, disfarces na linguagem, e muitas vezes, uma falta de compreensão" (OYĚWÙMÍ, 2018: p. 179). Esses fatos marcam a necessidade de repensar a categoria "mulher" e a subordinação do gênero a partir de preocupações imanentes às próprias realidades africanas.

estão ligadas às das mulheres em outras partes do mundo com as quais partilham solidariedade e apoio ao longo dos anos. Ao mesmo tempo, elas criticam as agendas políticas únicas ao reivindicar um feminismo situacional e localizado. Carta de princípios feministas para as feministas africanas. Disponível em https://www.geledes.org.br/wp-content/uploads/2017/04/AFF-Feminist-Charter-Digital-\%E2\%80\%93Portuguese.pdf Acesso em 08/11/2018. p. 12. 
Neste sentido, conforme aponta Uma Narayan em O projeto da epistemologia feminista: perspectivas de uma feminista não ocidental, as feministas não ocidentais "enfrentam uma luta dupla para tentar encontrar sua própria voz: devem aprender a articular suas diferenças, não só em relação aos seus próprios contextos tradicionais, mas também em relação ao feminismo ocidental" (NARAYAN, 1997: p. 284).

Landaluze e Espel (2014) acrescentam que os feminismos ocidentais se chocam com a visão holística e comunitárias das sociedades africanas onde o indivíduo possui um contexto e não pode existir fora dele. Apontam que a luta por igualdade deve estar centrada na comunidade ou família, mais do que nas mulheres e que, nesta perspectiva comunitária dos feminismos africanos, busca-se a igualdade de gênero com a participação dos homens (LANDALUZE; ESPEL, 2014: p. 50-52). Tal especificidade indicam-nos que a construção dos feminismos africanos não foi um movimento voltado exclusivamente para a igualdade entre mulheres e homens, mas a complexidade dessa dinâmica social, abordando inclusive a opressão do gênero.

Nesse sentido, utilizo o termo "feminismos africanos" para referir-me a material bibliográfico produzido por feministas negras africanas, e/ou acadêmicas negras africanas e ativistas, que independentemente de seu país de origem, no continente africano ou na Diáspora, têm buscado refletir partindo do ponto de vista africano, embora reconhecendo a imensa heterogeneidade que opera dentro dos limites deste termo.

\section{Interseccionando feminismos}

$\mathrm{Na}$ Diáspora, as intelectuais e feministas africanas encaram o racismo diariamente (ESPEL; LANDALUZE, 2014: p. 51). Desse modo, muitas vezes, as mulheres de descendência africana que abraçam o feminismo negro optam por essa escolha devido à ausência de uma estrutura adequada para suas necessidades individuais como mulheres africanas (EBUNOLUWA, 2009: p. 3) ${ }^{19}$.

Neste sentido, não é de estranhar a auto identificação das africanas com o pensamento das feministas negras, uma vez que são tocadas pelos racismos estruturantes, sendo elas negras e africanas. Contudo, trata-se de fatores que também sinalizam tensões em torno do pensamento

\footnotetext{
${ }^{19} \mathrm{O}$ pensamento feminista negro é aqui entendido como um conjunto de teorias ou pensamentos especializados produzidos por intelectuais afronorteamericanas, elaborados para expressar o ponto de vista de mulheres negras (COLLINS, 1998. p. 259). No EUA, trabalhos como os de Bell Hooks, Ângela Davis, Patrícia Hill Collins e outras têm combatido a invisibilidade das mulheres negras e trazido para a esfera pública um ponto de vista diferente. Não apenas as acadêmicas, mas musicistas, poetas, escritoras, artistas e outros que compõem este grande conjunto de intelectuais negras têm buscado interpretar as experiências destas mulheres negras.
} 
das feministas negras, pois embora não necessariamente as africanas sejam negras e sofram as opressões de raça na Diáspora, no contexto do continente africano tal estrutura toma outras proporções. O racismo também existe, embora com outras expressões. Como a raça é um aspecto importante para a reflexão feminista africana?

Patrícia Godinho Gomes (2016) narra que o significado de "raça" para os africanos vivendo em África não é o mesmo para os afrodescendentes do Novo Mundo (GOMES; FIGUEIREDO, 2016: p. 917). A pesquisadora chama atenção para o lugar situacional que a colonização, a exploração e o racismo, assim como as relações entre os africanos e os brancos, assumiu na experiência colonial fora de África, e papel dessas diferenças para a compreensão do racismo e das práticas discriminatórias.

Gomes alerta, no caso da Guiné, e também para alguns países de colonização portuguesa, que a mestiçagem justificou e foi motivo de relações vantajosas e distinções sociais. Uma vez que "os mestiços estabeleceram relações privilegiadas com o poder colonial, tendo acesso às vantagens que o regime oferecia”. Foi desse modo que se estabeleceram distinções sociais, hierarquias e desigualdades, e as diferenças socioculturais no contexto de luta pelo poder político apareceram. Assim, o conceito de raça deve ser "pensado e compreendido como um fenômeno profundamente relacionado às próprias possibilidades de acesso ao exercício da cidadania no contexto do Estado colonial" (GOMES; FIGUEIREDO, 2016: p. 918).

A investigadora explica que na Guiné Bissau, a liderança do PAIGC, entre os quais Amílcar Cabral, pertencia a uma elite mestiça, com acesso às vantagens estabelecidas pelo poder colonial instituído, no que se refere à formação e emprego; quem assume o poder e liderança no contexto do Estado independente.

Para o caso dos sujeitos considerados "indígenas", excluídos do exercício de cidadania, com origem nos diferentes grupos étnicos de Bissau e que constituem grande maioria da população, historicamente, no quadro da colonização portuguesa, as possibilidades educativas, de acesso e ascensão social, foram limitadas. No período colonial, usufruem de uma instrução de base pelas missões católicas e depois, já no processo de construção do novo Estado nacional, são marginalizados. O que gerou fraturas, tensões e repercutiu inclusive nas relações de gênero, engendrando hierarquias e distinções sociais entre as próprias mulheres, particularmente entre as mulheres da cidade e do campo. 
Portanto, são articulações que foram estruturando-se hierarquicamente em termos de classe e de gênero, em que o colonialismo teve impacto significativo, principalmente em vista da dicotomia campo-cidade. $\mathrm{O}$ que espelha e perspectiva, além das categorias de raça, as diferenças culturais e étnicas próprias do contexto africano (GOMES; FIGUEIREDO, 2016: p. 918).

O que autora procura evidenciar é que no continente, as mulheres africanas buscam resgatar sua identidade prioritariamente na luta dupla contra as opressões colonial e patriarcal. Aqui a categoria classe e raça também devem ser consideradas. Ou seja, não há uma exclusão da raça, mas existem ali outros marcadores raciais, que são elementos que não podem ser desconsiderados, em vista de seu contexto social, cultural e político.

Segundo Gomes, as mulheres que protagonizam a luta e apropriam-se do discurso nacional-emancipacionista dos movimentos de libertação tinha origem, em sua maior parte, nos centros urbanos da Guiné Bissau, muitas delas com formação assegurada no período colonial. Ainda que, por outro lado, os movimentos de mulheres tenham emergido substancialmente com base nas experiências das mulheres que viviam no meio rural, a maioria delas sem acesso à educação formal e de qualidade (GOMES; FIGUEIREDO, 2016: p. 918).

Portanto, para a pesquisadora, o uso do conceito de gênero parece ser mais elucidativo das compreensões das desigualdades dentro e fora do continente, uma vez que o conceito de raça e o racismo assumem dinâmicas distintas no continente e na Diáspora (GOMES; FIGUEIREDO, 2016: p. 909).

Neste sentido, o debate de raça, como elemento estruturante da sociedade, compartilhada pela experiência colonial, e relações de gênero, na articulação de ambas as identidades, são importantes para compreender as opções políticas destas feministas africanas, na Diáspora.

Trata-se de epistemologias que problematizam experiências locais e globais, que devem ser analisadas segundo suas especificidades, e serve de estímulo para a comunicação de uma cultura de resistência das mulheres, no continente africano e na Diáspora. E significa ruptura epistêmica nos estudos de gênero, que engloba o continente africano partindo de "conhecimento endógeno".Estamos aqui diante de tendências reflexivas que reivindicam uma abordagem mais localizada, diversa, sem desconsiderar a legitimidade das próprias africanas de comunicar/refletir acerca os problemas que assolam às realidades de África. 
Com efeito, o recente trabalho da pesquisadora Thuilia Farias Ferreira ${ }^{20}$ intitulada Africanas: gênero e feminismo em perspectiva afrocentrada ${ }^{21}$ endossa esta perspectiva ao refletir sobre o feminismo e questões de gênero no continente a partir do pensamento de intelectuais negras africanas, acadêmicas feministas e ativistas (FERREIRA, 2020). De acordo com Ferreira, é da dialética entre academia e ativismo que surgem definições, temas e significação epistemológica do(s) pensamento(s) feminista(s) africano(s), dando centralidade à experiência e cultura das mulheres africanas. Deste modo, desafiando as definições do discurso ocidental normatizado.

Publicada em 2020, a dissertação considera - exclusivamente - os escritos e estudos produzidos por africanas a partir do continente e da Diáspora.Segundo a pesquisadora, a maioria dos conceitos alternativos ao discurso ocidental que circula com maior incidência hoje foram cunhados por mulheres nigerianas, que "entre concordâncias e críticas dialogam em termos de teoria/produção acadêmica” (FERREIRA, 2020: p. 89), é o caso de Oyèrónkẹ Oyěwùmí, Ifi Amadiume, Chimamanda Ngozi Adichie, Amina Mama, Chikwenye Ogunyemi, Minna Salami, Besi Adeleye Fayemi.

Entretanto, independente do país africano, todos os formatos teóricos revelam a necessidade de refletir o contexto específico de cada mulher, bem como a partir dela, livrando-a dos resquícios de dominação colonialistas. São vias alternativas às perspectivas tradicionalistas ou ocidentalizadas sobre a mulher (FERREIRA, 2020: p. 117).

Ferreira (2020) assume que o "feminismo não foi importado do Ocidente e que existe uma longa história de resistência ao patriarcado na África”, antes mesmo do surgimento do "feminismo" enquanto designação e indicação de um projeto político global de luta por igualdade. Com vistas a "conhecer e compreender as articulações teóricas acerca da condição da mulher e da equidade de gênero no continente a partir da produção de intelectuais africanas”, a estudiosa sintetiza os formatos conceituais que revelam parte dessas teorizações de mulheres negras africanas e afro-diaspóricas, explica (FERREIRA, 2020: p. 142):

O Mulherismo da afro-estadunidense Alice Walker se coloca como uma teoria que abrange a totalidade das pessoas, mas parte da mulher negra - aqui, na verdade, a finalidade são todas as pessoas - inclusive homens e pessoas brancas. Na proposta da

\footnotetext{
${ }^{20}$ Thuilia Ferreira é parte do projeto biografia de mulheres africanas, coordenado pelo professor Rivair Macedo, que tem o objetivo pedagógico de sistematizar o maior número possível de informações sobre a vida de mulheres nascidas no continente africano, de modo a oferecer subsídios para o ensino e pesquisa em todos os níveis de educação, sobre a História do continente africano no Brasil. Consultar em https://www.ufrgs.br/africanas/. Acesso em 01/03/2021.

${ }^{21}$ Em síntese, é trabalho precursor no Brasil, realizado no esforço de reunir informações panorâmicas e indisponíveis em língua portuguesa, nas palavras da autora, que "podem sulear outras pesquisas em torno das temáticas". (FERREIRA, 2020: p. 8).
} 
nigeriana Chikwenye Ogunyemi, o Mulherismo precisa tomar distância não só do feminismo hegemônico, mas também dos feminismos negros da Diáspora, em prol das especificidades africanas no sentido geográfico, lembrando muito a ideia de afrocentrismo, de africanas em África para africanas em África, sem Diáspora. Já o Mulherismo Africana da afro-estadunidense Clenora Hudson-Weems, que ao se definir como aporte ideológico criado e destinado a todas as mulheres de ascendência africana, traz uma perspectiva que dialoga mais com a afrocentricidade, por ser pensada a partir da Diáspora para africanos em África e na Diáspora (sujeitos afro-diaspóricos).

Como podemos perceber, trata-se de abordagens que propõem um princípio de definição e novas proposições para o estudo de gênero. A grande preocupação formulada por estas designações conceituais, no entanto, é a recusa do termo "feminismo", entendido como um conceito que aprisiona, um replicador de perspectiva dominante ocidental.

Contudo, conforme mencionei anteriormente, nos termos deste artigo, o esforço aqui não é de categorizar ou classificar as obras das intelectuais africanas, mas analisar algumas implicações teóricas que o uso do termo trás, enraizados nas experiências particulares das mulheres africanas do continente. Trato, portanto, de tais teorias, a partir das reflexões em torno das articulações mulher-gênero-feminismo (s) africano (s), pois independemente de suas nuances conceituais, todos opõem-se efetivamente as estruturas sociais que promovem a discriminação e a opressão das mulheres (BAMISILE, 2013: p. 262).

É fato que independentemente do continente ou da raça, as mulheres padecem da opressão e exploração em vista de sua condição como mulher. O que as intelectuais africanas, ativistas, mulheres autodeclaradas feministas africanas e as mulheristas africanas assinalam, resguardadas suas nuanças, é o que os discurso que envolvem as mulheres africanas não podem escapar de outras questões históricas, como por exemplo, a questão do colonialismo, da escravidão e do etnocentrismo.

De outro modo, há que se ter atenção a forma particular como as sociedades tradicionais africanas estão organizadas. A questão da maternidade, citando caso onde as diferenças são nítidas, é considerado fator de prestígio em várias dessas sociedades africanas. Significativamente, o "feminismo" passa a ser entendido como um conceito estrangeiro às condições destas mulheres desde a sua criação, particularmente fazendo referência ao racismo e ao classismo, demonstrando o esvaziamento de uma perspectiva histórica e contemporânea centrada no continente africano.

A título de exemplo, no Brasil, a perspectiva mulherista de Clenora Hudson-Weems é muito difundida pelas intelectuais negras Katiúscia Ribeiro (2019) e Anin Urasse ${ }^{22}$. Contudo,

22 Urasse divulga suas ideias sobre o mulherismo africana em seu blog, ver em https://pensamentosmulheristas.wordpress.com/author/tradutoresnegros. Acesso em 24/07/2021. 
não necessariamente como uma teoria do feminismo africano, mas como um paradigma destinado a atender as necessidades das mulheres de descendência africana.

De agenda própria, o mulherismo africana de Hudson-Weems, busca distanciar-se do feminismo branco e do feminismo negro e, além do mais, no que diz respeito especificamente à terminologia, difere também do feminismo africano (HUDSON-WEEMS, 2020: p. 44).

É paradigma pensando a partir do gênero, mas diferentemente da compreensão de Gomes (2016), opera dentro da concepção de raça, seguindo o entendimento da afrocentricidade, na linha de Molefi Keti Asante ${ }^{23}$ (1988). Neste sentido, o sexismo é uma questão secundária, surgidas das problemáticas em torno da raça, classe e economia.

Por ser gerado para responder as necessidades próprias das mulheres brancas, HudsonWeens busca distanciar-se de qualquer aproximação com o feminismo de raiz europeia. Tal escolha justifica-se com base no evidente racismo que desde logo estabeleceria uma incompatibilidade com as mulheres africanas (BAMISILE, 2013: p. 274).

Nesta busca de demarcação da diferença, a procura de uma "variante africana", além do Womanism africano de Clenora Hudson -Weens dos EUA, o Womanism de Alice Walker, nos EUA; o Womanism de Chikwenye Ogunyemi e Mary Kolawole da Nigéria, cito como exemplo o Stiwanism de Molara Ogundipe-Leslie da Nigéria, o conceito de Misovire, cunhado por Werewere Liking, o conceito de Femalism de Chioma Opara, o de Gynism, cunhado pela filósofa e feminista africana, Pauline Marie Eboh, e o conceito de Gynandism de Chinweizu e Barnabe Bilongo (BAMISILE, 2013: p. 262). Trata-se de construções teóricas endêmicas, de alternativas conceituais ao feminismo euro-americano, as quais por questão de tempo e espaço não adensarei aqui.

Quer dizer, no continente e fora dele, as ideias dessas intelectuais têm sido agentes de um pensamento reflexivo. Elas buscam designar a luta da mulher africana em seus contextos particulares e a possibilidade do uso de outras nomenclaturas e aportes que não se utilizem do feminismo ocidental (FERREIRA, 2020: p. 35).

Ao discorrer sobre o aumento do ativismo no continente africano, Thuila afirma que isso é parte de um movimento que se fortalece principalmente nos anos 1990 devido aos debates e difusão de ideias no contexto internacional, maior financiamento de associações de mulheres e abertura política (de alguns países) a formação de organizações femininas.

\footnotetext{
${ }^{23}$ Segundo Molefi Asante, a afrocentricidade significa "colocar os ideais africanos no centro de qualquer análise que envolva a cultura e o comportamento africano” (ASANTE, 1988: p. 6).
} 
$\mathrm{Na}$ ótica de Thuila (2020) é fenômeno fortalecido também com o maior uso do termo "feminismo" por organizações de mulheres e nas produções teóricas de mulheres africanas (FERREIRA, 2020: p. 122). Nesse sentido, a academia e internet têm configurado espaços chaves para a articulação de tais feminismos africanos. Citando dados da Association for Women's Rights in Development, a autora refere que "39\% das organizações sobre gênero existentes em 2006 na África subsaariana foram formadas entre 1990 e 1999, e outros 32\% entre 2000 e 2005" (FERREIRA, 2020: p. 66).

Ou seja, o pensamento destes feminismos, além de base estratégica política e reflexão sobre a condição da mulher, em perspectiva situacional, vêm atendendo também a demanda das africanas por organização; "tão diversos quanto os contextos africanos são as formas de se pensar/teorizar a posição da mulher no continente africano" (FERREIRA, 2020: p. 117).

Como busquei demonstrar, os estudos que situam o debate de gênero em África buscam ir além da ideia simplista de que o continente é homogêneo e o gênero seja também um conceito universal. É uma categoria sutil de análise histórica, que historiciza a história dessas mulheres em diferentes contextos históricos.

Ao optar por uma perspectiva plural, voltada para a visibilidade das questões de cada país, sociedades ou grupos, as feministas africanas mostram que a emancipação que buscam não é apenas da dominação masculina, mas também do controle estrangeiro e do neocolonialismo. Nesse sentido, muitas vezes uniram-se aos homens na luta contra o imperialismo ocidental, o capitalismo e o racismo, deixando em segundo plano o sexismo.

$\mathrm{O}(\mathrm{s})$ feminismo (s) africano (s), neste sentido, compreende um projeto intelectual e ativista de interrogação, de desmembramento das estruturas e sistemas de poder - profundamente enraizadas nas concepções nacionalistas de Estado. Em resumo, são epistemologias que questionam conceitos universalistas, problematizando experiências locais e globais, que devem ser analisadas segundo suas especificidades.

Nos últimos anos, é da dialética entre ativismo e academia que surgiram definições, temas e significação epistemológica do (s) pensamento (s) feminista (s) africano (s), no continente e na Diáspora, dando centralidade a experiências de mulheres africanas. Debates e produções teóricas de iniciativas feministas africanas que desafiam as definições do discurso intelectual normatizado e afirmam o direito da existência e reconhecimento dos discursos críticos acerca estas distintas realidades. 


\section{Conclusão}

Ao longo do artigo procurei conferir visibilidade histórica e dizibilidade historiográfica às reflexões tecidas por pensadoras africanas, a partir da problematização das categorias mulhergênero-feminismos. A homogeneização da categoria "mulher" assim como a lógica da família nuclear patriarcal, a qual muitas vezes o feminismo tradicional se ancora, é uma forma de família inapropriadamente universalizada, o qual não se ajusta a realidades diversas e distintas como as africanas. Inclusive na nomenclatura. As experiências de raça e gênero são construídas socialmente.

Em Angola, os feminismos africanos constituem-se a partir de meados da década de 1970 do século XX, não exatamente como grupos, mas a partir de questões reflexivas, colocadas em seus contextos culturais e sociais. Antes disso, houveram sim "movimentos" de mulheres angolanas que nas lutas de independência combateram ao "lado dos homens". Não havendo, portanto, um diálogo explícito entre a movimentação dessas mulheres da luta armada e a luta feminista, embora as ideias de resistência e enfrentamento estivessem presentes enquanto práticas. Mais precisamente fazendo referência à um contexto maior da história - a história da escravidão, imperialismo, colonização, a dominação e controle do corpo das mulheres.

As lutas de libertação serviram como base de formação para o surgimento de Organização de Mulheres dentro dos movimentos de luta armada e, mais tarde, dos feminismos africanos. Dado a especificidade das organizações femininas, definidas em e a partir dos movimentos nacionalistas de libertação, e as concepções tradicionais de igualdade de gênero, as tensões entre aquelas que pretendiam adotar uma postura negociada com o Estado e aquelas que adotavam uma postura mais radical, de cobrança de direitos, impunidade e denuncia das delações de violências mais extremas - tanto de pessoas comuns quanto de militares - a exemplo das violações femininas, intensificou-se.

As feministas africanas constroem e buscam resgatar sua identidade na dupla luta, anticolonial e antipatriarcal. Aqui a categoria classe e raça também devem ser consideradas. Contudo, no que diz respeito à elaboração de determinado pensamento crítico, estas têm ocupado espaço marginal tanto no âmbito político quanto acadêmico, o que pude constatar ao realizar pesquisa sobre estas pensadoras, invisibilizadas tanto no interior do campo dos estudos de gênero, quanto nos chamados estudos africanos, este último concentrado nas problemáticas vindas principalmente da Diáspora. Busquei chamar atenção para a necessidade de ampliar o debate, contrastando e interseccionando feminismos. 


\section{Referências Bibliográficas}

ALVES, Branca Moreira; PITANGUY, Jaqueline. O que é feminismo. 8. ed. São Paulo: Brasiliense, 1991

ASANTE, Molefi Kete. The Afrocentric Idea. Philadelphia: Temple University Press, 1988.

BAMISILE, Sunday Adetunji. A procura de uma ideologia afro-cêntrica: do feminismo ao afrofeminismo. In: Via Atlântica, Vol. 24, p. 257-279. São Paulo: USP, 2013. Disponível em: <http://www.revistas.usp.br/viaatlantica/article/view/58303>. Acesso em: 28/07/2021.

CIRNE, Michelle. A produção necessária das intelectuais feministas africanas no campo dos estudos de gênero e a agência do Codesria. Revista África(s), v. 04, n. 08, pp. 104-114, jul./dez. 2017.

COLLINS, Hill. La política del pensamento feminista negro. In ¿Qué son los estúdios de mujeres?, NAVARRO, Marysa \& STIMPSON, R. Catharine (Orgs). Argentina, Buenos Aires: Fondo de Cultura Economica, 1998.

.O que é um nome? Mulherismo, Feminismo Negro e além disso. In: Caderno Pagu, v. $51,2017$.

Aprendendo com a outsider within: a significação sociológica do pensamento feminista negro. In: Revista Sociedade e Estado, Vol. 31, N. 1, p. 99-127, Janeiro/Abril 2016.

CORNELL, Drucilla; VAN MARLE, Karin. Ubuntu feminism: Tentative reflections. Verbum et Ecclesia. 36(2), Art. \#1444. Disponível em https://verbumetecclesia.org.za/index.php/ve/article/view/1444/2493, (traduzido para uso didático por Juliana Gonçalves Caceres).

COSTA, R. Colonialismo e gênero entre os Ovimbundu: relações de poder no Bailundo (18801930). 2014. 205 f., il. Tese (Doutorado em História)

CURTO, José. "The Donas of Benguela,1797: A preliminary Analysis of a Colonial Female Elite”, in PANTOJA et al. (orgs.) Angola e as angolanas: memória, sociedade e cultura. São Paulo: Intermeios, 2016.

EBOH, Marie Pauline. Androcentric web and gynist philosophy. Quest: An African Journal of Philosophy. Vol. XIV, no 1-2. 2000.(tradução para uso didático de Marie Pauline Eboh).

EBUNOLOWA, Stounsa Mobolanle. Feminism: The quest for na African Variant. The Journal Pan African Studies, vol 3, n. 1, 2009, p. 227-234 (traduzido para uso didático por Luanda Cristina Munõz Roriz).

ERRÁEZ, Ximena Ron. Hacia la desoccidentalización de los feminismos - Un análisis a partir de las perspectivas feministas poscoloniales de Chandra Mohanty, Oyeronke Oyewumi y Aída Hernández In Realis, v 4, no 1, Jan-Jun. 2014.

ESPEL, Idarraga Leire; LANDALUZE, Iker Zirion. Los feminismos africanos. Las mujeres africanas "en su próprios términos" In Relacioines Internacionales, número 27, Octubre 2014, Enero 2015.

FERREIRA, Aurora da Fonseca. A contribuição da mulher na formação do saber e do conhecimento. In A mulher em África. Vozes de uma margem sempre presente. MATA, Inocencia \& PADILHA, Laura Cavalcante. Lisboa: Edições Colibri, 2018. 
FERREIRA, Thuilia Farias. Africanas: gênero e feminismo em perspectiva afrocentrada. Universidade Federal do Rio Grande do Sul: Porto Alegre, 2020. Dissertação de Mestrado.

GOMES, Patrícia Godinho \& FIQUEIREDO, Angela. Para além dos feminismos: uma experiência comparada entre Guiné-Bissau e Brasil. In Rev. Estud. Fem. 24 (3) • Sep-Dec 2016. Disponível em https://www.scielo.br/j/ref/a/JmRGJdv7d678THNVjbL7hjv/abstract/?lang=pt. Acesso em 20/07/2021.

HUDSON-WEEMS, Clenora. Mulherismo africana, recuperando a nós mesmas. Tradução de Wanessa A. S. P. Yano. 1a ed. São Paulo: Editora Ananse, 2020.

KASEMBE, Dya. As mulheres honradas e insubmissas de Angola. Luanda Sul/Angola: Mayamba, 2010.

MCFADDEN, Patrícia. Perspectivas feministas africanas de pós-colonialidade. In AbeÁfrica: Revista da Associaçaõ Brasileira de Estudos Africanos. V. 04, n. 04, abril de 2020. Disponível em https://revistas.ufrj.br/index.php/abeafrica/article/view/40935/22507. Acesso em 24/07/2021.

MATA, Inocência. Estudos Pós-Coloniais. Desconstruindo Genealogias Eurocêntricas. In Civitas, Porto Alegre,vol. 14, n. 1, p. 27-42, jan.-abr. 2014, p. 31. Disponível em http://revistaseletronicas.pucrs.br/ojs/index.php/civitas/article/view/16185/10957. Acesso em 05 de Julho de 2017.

MOUZINHO, Aurêa; CUTAIA, Sizaltina. Reflections on Feminist Organising in Angola. In Feminist African. N. 22, 2017. Disponível em http://www.agi.ac.za/agi/feminist-africa/22. Acesso em 17/05/2021.

NARAYAN, Uma. O projeto da epistemologia feminista: perspectivas de uma feminista não ocidental. In Gênero, Corpo, conhecimento/ JAGGAR, Alison M \& BORDO, Susan R. (Orgs); traduçãoo de Britta Lemos de Freitas. - Rio de Janeiro: Record: Rosa dos Tempos, 1997.

OLIVEIRA, Vanessa dos Santos, "Donas pretas livres e escravas em Luanda (séc. XIX), In Estudos Ibero-Americanas, 44, 3 (2018). p. 447-456.

OYĚWÙMÍ, Oyèrónké. Conceitualizando o gênero: os fundamentos dos conceitos feministas e o desafio das epistemologias africanas. In Decolonialidade e pensamento afrodiaspórico, COSTABERNARDINO, Joaze; TORRES-MALDONADO \& GROSFOGUEL, Ramon. (Orgs.) 1 ed. Belo Horizonte: Autência Editora, 2018.

PAULINE, Marie. Androcentric web and gynist philosophy. Quest: An African Journal of Philosophy. Vol. XIV, No. 1-2, 2000, p. 103-111 (traduzido para uso didático por Olga Rodrigues de Lima Souza)

PANTOJA, Selma. Conexões e identidades de gênero no caso Brasil e Angola, Sécs. XVIII e XIX. Disponível em http://bibliotecavirtual.clacso.org.ar/ar/libros/aladaa/pantoja.rtf. Acesso em 18/04/2019 e.

. e THOMPSON E. As culturas africanas na encruzilhada dos mundos. In: PANTOJA, S; BERGAMO, E. (Org.). África contemporânea em cena - perspectivas interdisciplinares. São Paulo: Intermeios, 2015.

PEREGRINO, Miriane. Muhatu e a virada do spoken word em Angola. In Mulemba, V. 11, n. 21, 2019. Disponível em https://revistas.ufri.br/index.php/mulemba/article/view/31264. Acesso em 14/05/2021. 
RABELLO, Rosana Baú. Dya Kassembe e a representação das vozes de mulheres angolanas. In Caderno Seminal Digital, ano 23, n 27, v. 1, jan-jun/2017.

REIS, Maria do Céu Carmo. Représentation sociale de la Femme dans le Discours Nationaliste: Le cas de la Génération des années 50 em Angola. In África, Revista do Centro de Estudos Africanos da USP, no 10, 1987.

RIBEIRO, Katiúsica \& NJERI, Aza. Mulherismo africana: práticas na Diáspora brasileira. In Curriculo sem Fronteiras, v. 19, n. 2, p. 595-608, maio/ago. 2019. Disponível em https://pdfs.semanticscholar.org/2d47/dfa528d9af54df758d0cc6cce91f0afcc9e7.pdf

SOW, Fatou. "The social sciences in Africa and gender analysis". In: Iman, A.; Mama, A.; Sow, (eds.). Engendering African Social Sciences. Dakar: CODESRIA Book Series, 1997 apud CIRNE, Michelle. A produção necessária das intelectuais feministas africanas no campo dos estudos de gênero e a agência do Codesria. Revista África(s), v. 04, n. 08, p. 104-114, jul./dez. 2017.

\section{Fontes}

Jornal Província de Angola, fevereiro de 1972.

Jornal Diário de Luanda. 04 de julho de 1975.

\section{Arquivo}

Arquivo da Biblioteca Nacional de Angola.

Sobre a autora:

Dayane Augusta Santos da Silva: Possui graduação (2009) e mestrado (2014) em História pela Universidade de Brasília. É doutoranda em História pela mesma Universidade. Atua como professora de História no Instituto Federal de Brasília (IFB). Foi professora de História no Instituto Federal de Goiás (IFG). Compôs o Núcleo Docente e estruturante do curso de Ciências Sociais do campus Formosa (NDE/IFG/FSA). É integrande da Rede de Historiadorxs negrxs. Tem experiência na área de História, com ênfase em História do Brasil do período colonial e História de Angola, particularmente no campo da História das mulheres no contexto de luta anticolonial. Possui experiência nos debates relacionados a temática da escravidão, colonialismo, estudos pós-coloniais, historiografia e discussões de gênero em Angola.

Artigo recebido para publicação em: 15 de março de 2021.

Artigo aprovado para publicação em: 22 de agosto de 2021.

\section{Como citar:}

SILVA, Dayane Augusta Santos da. Gênero e os feminismo(s) aficano(s). Revista Transversos. Dossiê: Africanizar: resistências, resiliências e sensibilidades. Rio de Janeiro, nº. 22, 2021. pp. 268-287. Disponível em: $\quad<$ http://www.e-publicacoes.uerj.br/index.php/transversos>. ISSN 2179-7528. DOI: $10.12957 /$ transversos.2021.58416

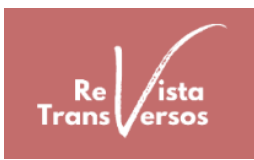

